\title{
Numerical Study of an Inventory Model for Deteriorating Items Having Demand as a Non-Linear Function of Time with Variable Cycle Lengths
}

\author{
K.Srinivasa Rao ${ }^{1}$,V.V.S.S.V.Prasad Rao Patnaik ${ }^{2}$,M.D.P.Patnaik ${ }^{3}$ \\ ${ }^{1}$ Department of Statistics,Andhra University, Visakhapatnam,India \\ ${ }^{2}$ Department of Mathematics,M,R,College(A),Vizianagaram,India,prasad_vvs07@yahoo.co.in \\ ${ }^{3}$ Department of Mathematics, $M, R$,College(A),Vizianagaram,India
}

\begin{abstract}
Inventory models play a major role in analysing the situations arising at places like food, vegetable markets, ware houses, textile markets, etc. In this paper we consider an inventory model for deteriorating products having demand which is function of a non linear function of time. and the cycle length of successive replenishments is a variable in the planning period. It is assumed that the cycle length in each cycle decreases in Arithmetic Progression. Shortages are allowed and are completely backlogged. The instantaneous state of inventory with shortages is derived. The total cost function of the horizon is obtained with suitable costs. The optimal pricing and ordering policies of the model are derived. The objective is to determine a replenishment policy that minimizes the total inventory cost. The model is illustrated with some numerical results. It is observed that the variable cycle length has a significant influence on optimal operating policies. This model also includes several models of the previous models for various values of the parameters.
\end{abstract}

Keywords: Perishable Inventory, Cycle Length, Demand Rate and Cost Function, Optimal Ordering Policies and Sensitivity Analysis.

\section{Introduction}

Much emphasis is given on developing and analyzing inventory models of deteriorating items. Many researchers have studied the effect of lifecycle of goods under consideration on the inventory control. Nahimias (1982), Rafat (1991), Giri and Goyal (2001) have reviewed the Inventory models of deteriorating items. Roy and Chauduri, (2007); have developed an EOQ model for deteriorating items with price dependent demand and special sales. Pal, M. \& Ghosh, S. K. (2008) have studied an Inventory Model with Stock Dependent Demand and General Rate of Deterioration under Conditions of Permissible Delay in Payments. Sankar Sana, (2007) studied an EOQ model for seasonal goods. Panda, Senapathi and Basu, (2009); have developed a single cycle perishable inventory model with time dependent quadratic ramp type demand and partial backlogging. They assumed that deterioration of inventory starts after a certain time. Roy and Chauduri, (2010); have studied an inventory model for a perishable item assuming that the demand rate depend not only on time but also on the selling price of the item. In all these models it is customary to consider that the cycle length (time lapse between two successive replenishments) of the system is fixed. However in many of the inventory situations arising at places like market yards dealing with food grains, food and vegetable markets, beverages it is a common phenomenon that the cycle length is not fixed and is a variable. Very little work has been reported in literature regarding inventory models with variable cycle lengths, except the works of Datta \& Paul in 1992, Bunia and Maitti in 1997.They have considered that the demand is a linear function of the form $a+b t, a>0, b>0$. But in some situations the demand is a non-linear function of time. Hence in this paper we develop and analyse an inventory model for demand as a non-linear function of time of the form $R(t)=a e^{b t}, a>0,0<b<1$. It is also further assumed that the cycle length in each cycle is a variable and the cycle lengths have a pattern of declining in Arithmetic progression. Using the differential equations, the instantaneous state of Inventory at each cycle is derived with suitable cost considerations. The total cost function is obtained. By minimizing the total cost function, the optimal cycle lengths and ordering quantities are derived. This model also includes several of the earlier models as particular cases for specific and limiting cases of the parameters.

\section{Assumptions And Notations}

1. We have considered an inventory model with the following assumptions and notations

2. The demand rate $\mathrm{R}(\mathrm{t})$ at any instant " $t$ " is of the form $R(t)=a e^{b t}, a>0,0<b<1$

3. Replenishment is instantaneous.

4. The entire planning Horizon of the system was taken as $\mathrm{H}$ units of time and is known. Inventory level is zero at times $\mathrm{t}=0$ and $\mathrm{t}=\mathrm{H}$. 
5. Lead time is zero.

6. Shortages are allowed and are fully backlogged and shortages are not allowed in the final cycle.

7. $\mathrm{T}_{\mathbf{i}}$ is the total time elapsed up to and including the $i^{\text {th }}$ cycle $(i=1,2, \ldots, \mathrm{m})$, where $\mathrm{m}$ denotes the total number of replenishments to be made during the prescribed time horizon $\mathrm{H}$. Hence $\mathrm{T}_{\mathbf{0}}=0$ and $\mathrm{T}_{\mathbf{m}}=\mathrm{H}$.

8. $t_{i}$ is the time at which the inventory level in the $i^{\text {th }}$ cycle reaches zero $\quad(i=1,2, \ldots, m-1)$.

9. $\mathrm{T}$ is the length of first replenishment cycle and $\mathrm{w}$ is the rate of reduction of the successive cycle lengths.

10. The on hand inventory deteriorates at a constant rate $\theta(0<\theta<1)$ per unit time and there is neither repair nor replenishment of the deteriorated inventory during $\mathrm{H}$.

11. The inventory holding cost $c_{1}$ per unit per unit time, the shortage cost $c_{2}$ per unit time, the unit cost $c$ and the replenishment cost (ordering cost) $c_{3}$ per replenishment are known and constant during the planning time horizon $\mathrm{H}$.

\section{Development Of The Model}

Let $\mathrm{I}_{\mathbf{i}}(\mathrm{t})$ denotes the inventory at time " $\mathrm{t}$ " during the $\mathrm{i}^{\mathrm{th}}$ cycle $\left(T_{i-1} \leq t \leq t_{i} ; i=1,2 \ldots m\right)$

The differential equations governing the system during the $\mathrm{i}^{\text {th }}$ cycle are

$\frac{d}{d t} I_{i}(t)=-R(t)-\theta \cdot I_{i}(t)$

This implies $\frac{d}{d t} I_{i}(t)+\theta \cdot I_{i}(t)=-a e^{b t} ; T_{i-1} \leq t \leq t_{i} ; i=1,2 \ldots m$

and $\frac{d}{d t} I_{i}(t)=-a e^{b t} ; t_{i} \leq t \leq T_{i} ; i=1,2 \ldots m-1$

with the initial conditions $I_{i}(t)=0$ at $\mathrm{t}=\mathrm{t}_{\mathbf{i}}$ for all $i=1,2, \ldots, m-1$.

From (1) $\frac{d}{d t}\left(e^{\theta t} \cdot I_{i}(t)\right)=-a e^{(b+\theta) t}$

Using the initial condition and solving the above equation we get

$I_{i}(t)=\frac{a e^{b t_{i}}}{b+\theta}\left[e^{\theta\left(t_{i}-t\right)}-e^{b\left(t-t_{i}\right)}\right]$

$T_{i-1} \leq t \leq t_{i} ; i=1,2, \ldots m$

Solving the equation (2) and using the initial condition we get

$I_{i}(t)=\frac{a e^{b t_{i}}}{b}\left(1-e^{\mathrm{b}\left(t-t_{i}\right)}\right) ; t_{i} \leq t \leq T_{i} ; i=1,2, \ldots m-1$

Now $T_{i}=i . T-\frac{i(i-1)}{2} w, i=0,1,2, \ldots, m-1$

and $\mathrm{T}_{\mathrm{i}}-\mathrm{T}_{\mathrm{i}+1}=\mathrm{T}-(\mathrm{i}-1) \mathrm{W}$

Also $\sum_{i-1}^{m} T-(i-1) w=H$

Hence $T=\frac{(m-1)}{2} w+\frac{H}{m}$

Let $\mathrm{D}\left(\mathrm{T}_{\mathbf{i}}\right)$ denote the number of deteriorated items in the $\mathrm{i}^{\text {th }}$ cycle $\left(\mathrm{T}_{\mathrm{i}-1}, \mathrm{~T}_{\mathbf{i}}\right)$ for all $\mathrm{i}=1,2, \ldots . \mathrm{m}-1$.

Hence $D\left(T_{i}\right)=\theta \int_{T_{i-1}}^{t_{i}} I_{i}(t) d t$

$$
=\frac{a \cdot \theta \cdot e^{b t_{i}}}{b+\theta} \int_{T_{i-1}}^{t_{i}}\left(e^{\theta\left(t_{i}-t\right)}-e^{b\left(t-t_{i}\right)}\right) d t
$$

The number of deteriorated items in the last cycle $\left(\mathrm{T}_{\mathbf{m}-\mathbf{1}}, \mathrm{T}_{\mathbf{m}}\right)$ i.e. $\left(\mathrm{T}_{\mathbf{m}-\mathbf{1}}, \mathrm{H}\right)$ is

$$
\begin{aligned}
D\left(T_{m}\right) & =\theta \int_{T_{m-1}}^{H} I_{m}(t) d t \\
& =\frac{a \cdot \theta \cdot e^{b H}}{b+\theta} \int_{T_{m-1}}^{H}\left(e^{\theta(H-t)}-e^{b(t-H)}\right) d t
\end{aligned}
$$

The loss of revenue due to deterioration in the $\mathrm{i}^{\text {th }}$ cycle is $L\left(T_{i}\right)$. Then by equation (9) $L\left(T_{i}\right)=C . D\left(T_{i}\right)$ 


$$
=\frac{c \cdot a \cdot \theta \cdot e^{b t_{i}}}{b+\theta} \int_{T_{i-1}}^{t_{i}}\left(e^{\theta\left(t_{i}-t\right)}-e^{b\left(t-t_{i}\right)}\right) d t
$$

The back log in the $\mathrm{i}^{\text {th }}$ cycle $\left(T_{i-1}, T_{i}\right)$ is $B\left(T_{i}\right)=\left(T_{i}-t_{i}\right) a \cdot e^{b t}$

Hence the ordering quantity in the $\mathrm{i}^{\text {th }}$ cycle $\left(T_{i-1}, T_{i}\right)$ is

$\mathrm{Q}_{\mathrm{i}}=$ Deterioration in the $\mathrm{i}^{\text {th }}$ cycle + Demand in the $\mathrm{i}^{\text {th }}$ cycle + Back log demand in the $(\mathrm{i}-1)^{\text {th }}$ cycle.

$=D\left(t_{i}\right)+\left(t_{i}-t_{i-1}\right) R(t)$

Using the equation (9) we get

$Q_{i}=\frac{a \cdot \theta \cdot e^{b t_{i}}}{b+\theta} \int_{T_{i-1}}^{t_{i}}\left[e^{\theta\left(t_{i}-t\right)}-e^{b\left(t-t_{i}\right)}\right] d t$

$+\left(t_{i}-t_{i-1}\right) a e^{b t}$

For the m cycles ordering cost $=m \cdot C_{3}$

Inventory during the $\mathrm{i}^{\text {th }}$ cycle $(1 \leq i \leq m-1)$

$=\int_{T_{i-1}}^{t_{i}} \frac{a e^{b t_{i}}}{b+\theta}\left[e^{\theta\left(t_{i}-t\right)}-e^{b\left(t-t_{i}\right)}\right] d t$

Inventory in the last cycle $\left(\mathrm{T}_{\mathrm{m}-1}, \mathrm{H}\right)$

$$
=\int_{T_{m-1}}^{H} \frac{a e^{b H}}{b+\theta}\left[e^{\theta(H-t)}-e^{b(t-H)}\right] d t
$$

From the equation (15) and equation (16) we get the hold cost of the inventory in all cycles as

$$
\begin{aligned}
& \sum_{i=1}^{m-1}\left\{\frac{a \cdot c_{1}}{b+\theta} \int_{T_{i-1}}^{t_{i}} e^{b t_{i}}\left[e^{\theta\left(t_{i}-t\right)}-e^{b\left(t-t_{i}\right)}\right] d t\right\} \\
& +\frac{a \cdot c_{1}}{b+\theta} \int_{T_{m-1}}^{H} e^{b H}\left[e^{\theta(H-t)}-e^{b(t-H)}\right] d t
\end{aligned}
$$

From the equation (11) the loss of revenue due to deterioration in the $\mathrm{i}^{\text {th }}$ cycle $L\left(T_{i}\right)(1 \leq i \leq m-1)$ is

$$
L\left(T_{i}\right)=\frac{c \cdot a \cdot \theta \cdot e^{b t_{i}}}{b+\theta} \int_{T_{i-1}}^{t_{i}}\left[e^{\theta\left(t_{i}-t\right)}-e^{b\left(t-t_{i}\right)}\right] d t
$$

Loss of revenue due to deterioration in the last cycle $\left(T_{m-1}, H\right)$

$$
=\frac{c \cdot a \cdot \theta \cdot e^{b H}}{b+\theta} \int_{T_{m-1}}^{H}\left[e^{\theta(H-t)}-e^{b(t-H)}\right] d t
$$

By the equations (18) and (19), we get the loss of revenue due to deterioration in all the $\mathrm{m}$ cycles as

$$
\begin{aligned}
\sum_{i=1}^{m-1}\left[\frac{c \cdot a \cdot \theta \cdot e^{b t_{i}}}{b+\theta} \int_{T_{i-1}}^{t_{i}} e^{\theta\left(t_{i}-t\right)}-e^{b\left(t-t_{i}\right)} d t\right] \\
+\frac{c \cdot a \cdot \theta \cdot e^{b H}}{b+\theta} \int_{T_{m-1}}^{H}\left(e^{\theta(H-t)}-e^{b(t-H)}\right) d t
\end{aligned}
$$

Shortage cost in the $\mathrm{i}^{\text {th }}$ cycle $(1 \leq i \leq m-1)$

$$
=c_{2} \int_{t_{i}}^{T_{i}} \frac{a}{b} e^{b t_{i}}\left(1-e^{b\left(t-t_{i}\right)}\right) d t
$$

Hence the total shortage cost for $m$ cycles

$$
=\sum_{i=1}^{m-1} c_{2} \int_{t_{i}}^{T_{i}} \frac{a}{b} e^{b t_{i}}\left(1-e^{b\left(t-t_{i}\right)}\right) d t
$$

(Because the last cycle does not contain the shortages)

Hence the total cost function,

$k\left(m, t_{i}, T_{i}\right)=m \cdot c_{3}+\sum_{i=1}^{m-1} \frac{a \cdot c_{1}}{b+\theta} \int_{T_{i-1}}^{t_{i}} e^{b t_{i}}\left[e^{\theta\left(t_{i}-t\right)}-e^{b\left(t-t_{i}\right)}\right] d t$ 


$$
\begin{aligned}
& +\frac{a \cdot c_{1}}{b+\theta} \int_{T_{m-1}}^{H} e^{b H}\left[e^{\theta(H-t)}-e^{b(t-H)}\right] d t \\
& +\sum_{i=1}^{m-1} \frac{c \cdot a \cdot \theta \cdot e^{b t_{i}}}{b+\theta} \int_{T_{i-1}}^{t_{i}}\left(e^{\theta\left(t_{i}-t\right)}-e^{b\left(t-t_{i}\right)}\right) d t \\
& +\frac{c \cdot a \cdot \theta \cdot c^{b H}}{b+\theta} \int_{T_{m-1}}^{H}\left[e^{\theta(H-t)}-e^{b(t-H)}\right] d t \\
& \left.\quad-\sum_{i=1}^{m-1} c_{2} \int_{t_{i}}^{T_{i}} \frac{a}{b} e^{b t_{i}}\left(1-e^{b\left(t-t_{i}\right)}\right) d t\right] \\
& k\left(m, t_{i}, T_{i}\right)=m \cdot c_{3}+\sum_{i=1}^{m-1}\left\{\frac{a\left(c_{1}+\theta c\right)}{b+\theta} \int_{T_{i-1}}^{t_{i}} e^{b t_{i}}\left[e^{\theta\left(t_{i}-t\right)}-e^{b\left(t-t_{i}\right)}\right] d t\right. \\
& \left.\quad-\frac{a c_{2}}{b} \int_{t_{i}}^{T_{i}} e^{b t_{i}}\left(1-e^{b\left(t-t_{i}\right)}\right) d t\right\} \\
& +\frac{a\left(c_{1}+\theta c\right)}{b+\theta} \int_{T_{m-1}}^{H} e^{b H}\left[e^{\theta(H-t)}-e^{b(t-H)}\right] d t
\end{aligned}
$$

\section{Optimal Ordering Policies of The Model}

The optimal ordering policies of the Inventory system are obtained by minimising the total cost function given in the equation (22). For a fixed $\mathrm{m}$ the corresponding optimal values of $t_{\mathbf{i}}(\mathrm{i}=1,2, \ldots \mathrm{m}-1)$ are obtained as the solutions of the system of (m-1) equations

$$
\frac{\partial}{\partial t_{i}}\left(k\left(m, t_{i}, T_{i}\right)\right)=0(i=1,2, \ldots, m-1) \text { and } \frac{\partial^{2}}{\partial t_{i}^{2}}\left(k\left(m, t_{i}, T_{i}\right)\right)>0
$$

Hence for a fixed $i$,

$$
\begin{aligned}
& \frac{\partial}{\partial t_{i}}\left(k\left(m, t_{i}, T_{i}\right)\right)=0 \\
& \Rightarrow \frac{a \cdot c_{2} \mathrm{v}}{b+\theta}\left[-e^{b t_{i}}\left(\frac{b+\theta}{\theta}\right)+e^{b t_{i}} e^{\theta\left(t_{i}-T_{i-1}\right)}\left(\frac{b+\theta}{\theta}\right)\right] \\
& -a c_{2} e^{b t_{i}}\left(T_{i}-t_{i}\right)=0 \text { where } \mathrm{v}=\frac{c_{1}+\theta c}{c_{2}}
\end{aligned}
$$

Expanding $e^{\theta\left(t_{i}-T_{i-1}\right)}$ by using the power series expansion and neglecting higher powers of $\square$ as they are small we get

$$
t_{i}=\frac{T_{i}+\mathrm{v} \cdot T_{i-1}}{1+\mathrm{v}} ; i=1,2, . . m
$$

This gives the optimal values of $t_{i}$ for which the total cost function is minimnum.

From the equation (22) we have

$$
\begin{aligned}
& k\left(m, t_{i}, T_{i}\right)=m \cdot c_{3}+\sum_{i=1}^{m-1}\left\{\frac{\left(c_{1}+\theta c\right) a}{b+\theta}\left[\frac{e^{b t_{i}}}{-\theta}\left(1-e^{\theta\left(t_{i}-T_{i-1}\right)}\right)-\frac{e^{b t_{i}}}{b}\left(1-e^{b\left(T_{i-1}-t_{i}\right)}\right)\right]\right. \\
& \left.\frac{-a c_{2}}{b}\left[e^{b t_{i}}\left(T_{i}-t_{i}\right)-\frac{e^{b t_{i}}}{b}\left(e^{\left(T_{i}-t_{i}\right)}-1\right)\right]\right\} \\
& +\frac{a\left(c_{1}+\theta c\right)}{b+\theta}\left[\frac{e^{b H}}{-\theta}\left(1-e^{\theta\left(H-T_{m-1}\right)}\right)-\frac{e^{b h}}{b}\left(1-e^{\left(T_{m-1}-H\right)}\right)\right]
\end{aligned}
$$


Expanding by $e^{\theta\left(t_{i}-T_{i-1}\right)}, e^{b\left(T_{i-1}-t_{i}\right)}, e^{\theta\left(H-T_{m-1}\right)}, e^{b\left(T_{m-1}-H\right)}$ by using the power series expansion and neglecting $3^{\text {rd }}$ and higher powers and on simplification we get

$$
\begin{aligned}
& k\left(m, t_{i}, T_{i}\right)=m \cdot c_{3}+\sum_{i=1}^{m-1} \frac{a\left(c_{1}+\theta c\right)}{2} e^{b t_{i}}\left(t_{i}-T_{i-1}\right)^{2} \\
& +\frac{a \cdot c_{2} \cdot b}{2}\left[\sum_{i=1}^{m-1} e^{b t_{i}}\left(T_{i}-t_{i}\right)^{2}+\frac{a\left(c_{1}+\theta c\right)}{2} e^{b H}\left(H-T_{m-1}\right)^{2}\right.
\end{aligned}
$$

Substituting for $\mathrm{t}_{\mathbf{i}}$ from (23) in the above equation, $k\left(m, t_{i}, T_{i}\right)$ will become a function of two variables $\mathrm{m}$ and $\mathrm{T}_{\mathrm{i}}$ only and hence we denote this by $\mathrm{k}\left(\mathrm{m}, \mathrm{T}_{\mathrm{i}}\right)$.

$$
\begin{aligned}
& \text { Hence } k\left(m, T_{i}\right)=m \cdot c_{3}+\frac{a\left(c_{1}+\theta c\right)}{2} \sum_{i=1}^{m-1} \frac{e^{b t_{i}}\left(T_{i}-T_{i-1}\right)^{2}}{(1+\mathrm{v})^{2}} \\
& +\frac{a . c_{2} \cdot b}{2} \sum_{i=1}^{m-1} \frac{e^{b t_{i}}\left(T_{i}-T_{i-1}\right)^{2}}{(1+\mathrm{v})^{2}}+\frac{a\left(c_{1}+\theta c\right)}{2} e^{b H}\left(H-T_{m-1}\right)^{2}
\end{aligned}
$$

Substituting for $T_{i}=i . T-i(\mathrm{i}-1) \frac{\mathrm{W}}{2}$ and $T_{i}-T_{i-1}=T-(\mathrm{i}-1) \mathrm{w}$ in (25) the total cost of function will become a function of three variables $m, \mathrm{w}, T$ is given by

$$
\begin{aligned}
& k(m, \mathrm{w}, T)=m \cdot c_{3}+\frac{a\left(c_{1}+\theta c\right)}{2(1+\mathrm{v})^{2}} \sum_{i=1}^{m-1} e^{b t_{i}}(T-(i-1) \mathrm{w})^{2} \\
& +\frac{a \cdot c_{2} \cdot \mathrm{v}^{2} \cdot b}{2(1+\mathrm{v})^{2}} \sum_{i=1}^{m-1} e^{b t_{i}}(T-(i-1) \mathrm{w})^{2} \\
& +\frac{a\left(c_{1}+\theta c\right)}{2} e^{b H}\left(H-(m-1) \mathrm{T}+(m-1)(m-2) \frac{\mathrm{w}}{2}\right)^{2}
\end{aligned}
$$

Substituting $T=(m-1) \frac{\mathrm{W}}{2}+\frac{\mathrm{H}}{\mathrm{m}}$, the cost function will become a function of two variables $\mathrm{m}$ and $\mathrm{w}$ only. Let it be $\overline{\mathrm{k}}(m, w)$. Here $\mathrm{m}$ is a discrete variable and $\mathrm{w}$ is a continuous variable. If $\mathrm{m}_{\mathbf{0}}>1$ is a given value of $\mathrm{m}$, then for this $\mathrm{m}_{0}$, the total cost function $\overline{\mathrm{k}}(m, w)$ will become a function of $\mathrm{w}$. The optimal value of $\mathrm{w}$ can be obtained by $\frac{d \bar{k}(w)}{\mathrm{dw}}=0$ such that the total cost function $\bar{k}(w)$ is minimum for this w.

Solving the equation $\frac{d \bar{k}(w)}{\mathrm{dw}}=0$. The optimal value $\mathrm{w}^{*}$ of $\mathrm{w}$ can be obtained. The corresponding optimal value of $\overline{\mathrm{k}}(m, w)$ is $\overline{\mathrm{k}}\left(m_{0}, w^{*}\right)$ and is obtained from the equation (25). The optimal value of $\mathrm{T}\left(=\mathrm{T}^{*}\right)$ and $\mathrm{T}_{\mathrm{i}}\left(T_{i}^{*}, i=1,2, . . m-1\right)$ can be obtained from the equations (8) and (5) respectively. Expanding $\mathrm{e}^{\theta\left(t-t_{i}\right)}, \mathrm{e}^{b\left(t-t_{i}\right)}$ and neglecting second and higher powers and on simplification we get

$$
Q_{i}=\frac{a \cdot \theta \cdot e^{b t_{i}}}{2}\left(t_{i}-T_{i-1}\right)^{2}+\left(t_{i}-t_{i-1}\right) a \cdot e^{b t}
$$

From the equations (26) and (27), the optimal ordering quantity of the $i^{\text {th }}$ cycle, total cost and cycle lengths for various values of the parameters $\theta, \mathrm{m}$ and costs $\mathrm{c}_{1}, \mathrm{c}_{2}, \mathrm{c}_{3}, \mathrm{c}$ for $\mathrm{a}=25, \mathrm{H}=12, \mathrm{~b}=1$ are computed and presented in the Table No.1. From this table we observe that $\mathrm{w}^{*}$ (The successive rate of reduction in cycle lengths) is an increasing function of $\theta$, the rate of deterioration, when other parameters and costs are fixed. As " $\theta$ " increases the optimal ordering quantity in each cycle is decreasing. However, total cost is increasing. When the ordering cost increases, $\mathrm{w}^{*}$ is increasing, but the ordering quantity in each cycle is decreasing when other parameters and costs are fixed. It is very interesting to note that the increases in ordering cost has no effect on successive reduction of cycle lengths and ordering quantities. However, the total cost is increasing for each cycle when 
other parameters and costs are fixed. If the cost per a unit increases the successive rate of reduction in each cycle $\mathrm{w}^{*}$ is increasing and the total cost is also increasing when the other parameters and costs remain fixed. When the penalty cost increases the rate of reduction in successive cycle lengths is increasing. This increases is very small when comparative to the other costs. It is also observed that the ordering quantities in each cycle is increasing significantly even though the cycle length is decreased. This is due to the non-linear growth (Exponential growth) of demand over time. This is the reason the total inventory cost is increasing significantly even though a slight increase in associated costs.

Table -1 (Optimal values of the parameters of the model with shortages a =25, H = 12)

\begin{tabular}{|l|l|l|l|l|l|l|l|l|l|l|l|l|l|}
\hline$\theta$ & $M$ & $C_{I}$ & $C_{2}$ & $C_{3}$ & $C$ & $w^{*}$ & $T_{1}{ }^{*}$ & $Q_{1}{ }^{*}$ & $T_{2}{ }^{*}$ & $Q_{2}{ }^{*}$ & $T_{3}{ }^{*}$ & $Q_{3}{ }^{*}$ & $K^{*}$ \\
\hline 0.02 & 3 & 0.2 & 5 & 9 & 2 & 2.625 & 6.625 & 18148 & 10.6 & 120091 & 12 & 5153310.47 & 2524386.88 \\
\hline 0.01 & 3 & 0.2 & 5 & 9 & 2 & 2.625 & 6.562 & 19544 & 10.5 & 127767 & 12 & 95424839.56 & 1561917.23 \\
\hline 0.01 & 3 & 0.1 & 5 & 9 & 2 & 2.375 & 6.375 & 95981 & 10.3 & 129974 & 12 & 41714229.11 & 1358641.76 \\
\hline 0.01 & 3 & 0.2 & 5 & 9 & 2 & 2.562 & 6.562 & 19544 & 10.5 & 127767 & 12 & 95424839.56 & 1561917.23 \\
\hline 0.01 & 3 & 0.2 & 4 & 9 & 2 & 2.552 & 6.552 & 18405 & 10.5 & 105559 & 12 & 50808177.50 & 1286072.94 \\
\hline 0.01 & 3 & 0.2 & 5 & 9 & 2 & 2.562 & 6.562 & 19544 & 10.5 & 127767 & 12 & 95424839.56 & 1561917.23 \\
\hline 0.01 & 3 & 0.2 & 5 & 9 & 2 & 2.562 & 6.562 & 19544 & 10.5 & 127767 & 12 & 95424839.56 & 1561917.23 \\
\hline 0.01 & 3 & 0.2 & 5 & 10 & 2 & 2.562 & 6.562 & 19544 & 10.5 & 127767 & 12 & 95424839.56 & 1561200.23 \\
\hline 0.01 & 3 & 0.2 & 5 & 9 & 2 & 2.562 & 6.562 & 19544 & 10.5 & 127767 & 12 & 95424839.56 & 1561917.23 \\
\hline 0.01 & 3 & 0.2 & 5 & 9 & 3 & 2.875 & 6.875 & 17509 & 10.8 & 164786 & 12 & 98869573.89 & 2473087.37 \\
\hline
\end{tabular}

Case (i) :

\section{Particular Cases}

For $\mathrm{m}=1$, the system reduces to a single period with finite time horizon. In such case the total cost for the period $\mathrm{H}$ is fixed and is

$k *(1)=c_{3}+\frac{a\left(c_{1}+\theta c\right)}{2} H \cdot e^{b H}$ It is obtained by substituting $\mathrm{m}=1$ in the equation (26).

The optimal ordering quantity $\mathrm{Q}^{*}$ is $Q^{*}=\frac{a \cdot \theta \cdot H^{2}}{2}$.

Hence this model reduces to the usual inventory model for deteriorating items with fixed lengths.

Case (ii) :

If the rate of deterioration $\theta \rightarrow 0$ in the above model, we obtain $t_{i}=\frac{T_{i}+\mathrm{v} \cdot T_{i-1}}{1+\mathrm{v}} ; i=1,2, \ldots, m$. Where $v=\frac{c_{1}}{c_{2}}$

The total cost function for the entire horizon $\mathrm{H}$ can be obtained from (26) and is

$k(m, \mathrm{w}, T)=m \cdot c_{3}+\frac{a \cdot c_{1}}{2(1+\mathrm{v})^{2}} \sum_{i=1}^{m-1} e^{b t_{i}}(T-(i-1) \mathrm{w})^{2}$

$+\frac{a \cdot c_{2} \cdot \mathrm{v}^{2} \cdot b}{2(1+\mathrm{v})^{2}} \sum_{i=1}^{m-1} e^{t_{i}}(T-(i-1) \mathrm{w})^{2}$

$+\frac{a \cdot c_{1}}{2} e^{b H}\left(H-(m-1) T+(m-1)(m-2) \frac{\mathrm{w}}{2}\right)^{2}$

This gives the optimal total cost for the inventory model for non-deteriorating items with variable cycle lengths. Putting $\theta=0$ in the equation (27), the optimal ordering quantity $Q_{i}^{*}$ is

$Q_{i}^{*}=\left(t_{i}-t_{i-1}\right) a e^{b t}, i=1,2, \ldots, m$

\section{Inventory Model Without Shortages}

When we assume that the shortages are not allowed there is no necessity of having backlog fulfillment. Then the parameter $t_{i}$ (The time at which shortages occur) considered earlier becomes $T_{i}(i=1,2, \ldots, m-1)$ and the shortage cost $\mathrm{c}_{2}$ is to be considered as $C_{2} \rightarrow \infty$,then the total cost function becomes. 


$$
\begin{gathered}
k(m, \mathrm{w}, T)=m \cdot c_{3}+\frac{a\left(c_{1}+\theta c\right)}{2} \sum_{i=1}^{m-1} e^{b t_{i}}(T-(i-1) \mathrm{w})^{2} \\
+\frac{a\left(c_{1}+\theta c\right)}{2} e^{b H}\left(H-(m-1) T+(m-1)(m-2) \frac{\mathrm{w}}{2}\right)^{2}
\end{gathered}
$$

If $\mathrm{m}$ is fixed on substituting $T=(m-1) \frac{\mathrm{W}}{2}+\frac{\mathrm{H}}{m}$, the total cost function will become a function of $w$. The optimal value $\mathrm{w}^{*}$ of $\mathrm{w}$ can be obtained by minimising the cost function.

The optimal ordering quantities $Q_{i}^{*}$ are given by

$$
Q_{i}^{*}=(T-(i-1) \mathrm{w})\left[(T-(i-1) \mathrm{w}) \frac{a \cdot \theta \cdot e^{b t_{i}}}{2}+a \cdot e^{b t}\right]
$$

From the equation (29) the optimal value of $\mathrm{w}^{*}$ for given values of $\mathrm{m} \& \mathrm{H}$ is not influenced by the parameter $\theta$ and the costs, $\mathrm{c}_{1}, \mathrm{c}_{3}, \mathrm{c}$ when the shortages are not allowed. However, the optimal ordering quantities in each cycle and total costs are much influenced by the changes in the parameters and costs, when the shortages are not allowed for the same value of $\theta$ and costs and number of cycles the optimal successive reduction rate is small for without shortages model than that of with shortages model. Also it is observed that the optimal ordering quantities for second model in each cycle is small as compared to without shortages model. This is due to the effect of shortage cost in the earlier model. If shortages are allowed for the same values of the parameters and costs the total cost of the model is more than that of without shortages model. This clearly shows that allowing

\begin{tabular}{|c|c|c|c|c|c|c|c|c|c|c|c|}
\hline$\theta$ & $m$ & $C_{1}$ & $C_{2}$ & $C$ & $w$ & $T_{I^{*}}$ & $Q_{1}^{*}$ & $T_{2}^{*}$ & $Q_{2}^{*}$ & $T_{2}{ }^{*}$ & $Q_{2}{ }^{*}$ \\
\hline 0.02 & 3 & 0.2 & 9 & 2 & 2.3 & 6.3 & 162347.17 & 10.3 & 10644277.55 & 12 & 55478696.73 \\
\hline 0.01 & 3 & 0.2 & 9 & 2 & 2.3 & 6.3 & 176943.66 & 10.3 & 10748341.71 & 12 & 55784204.75 \\
\hline 0.01 & 3 & 0.1 & 9 & 2 & 2.3 & 6.3 & 176943.66 & 10.3 & 10748341.71 & 12 & 55784204.75 \\
\hline 0.01 & 3 & 0.2 & 9 & 2 & 2.3 & 6.3 & 176943.66 & 10.3 & 10748341.71 & 12 & 55784204.75 \\
\hline 0.01 & 3 & 0.2 & 9 & 2 & 2.3 & 6.3 & 176943.66 & 10.3 & 10748341.71 & 12 & 55784204.75 \\
\hline 0.01 & 3 & 0.2 & 10 & 2 & 2.3 & 6.3 & 176943.66 & 10.3 & 10748341.71 & 12 & 55784204.75 \\
\hline 0.01 & 3 & 0.2 & 9 & 2 & 2.3 & 6.3 & 176943.66 & 10.3 & 10748341.71 & 12 & 55784204.75 \\
\hline 0.01 & 3 & 0.2 & 9 & 3 & 2.3 & 6.3 & 179645.42 & 10.3 & 10807806.95 & 12 & 55919901.56 \\
\hline
\end{tabular}
shortages has a tremendous influence on optimal ordering policies and scheduling cycle lengths in Table -2 .

Table -2 (Optimal values of the parameters of the model without shortages a =25, H=12)

\section{Summary And Conclusions}

This paper contributes to the descriptive and prospective modeling of some inventory systems for deteriorating items. These models have a wider applicability in analysing the inventory systems arising at places like fruit and vegetables markets, food processing industries, photochemical industries, oil and petroleum industries etc., various inventory models have been developed and analysed with various assumptions in order to suit for several different practical situations. The potential strings in the inventory modeling are demand pattern and cycle lengths (the time lapse between two successive replenishments). Several of the earlier models considered irrespective of the nature of demand, the cycle length is fixed for each cycle of planning in the finite horizon. This assumption is useful for situations considering EOQ models with infinite life time (Nonperishable items). However, for perishable items like food grains, sea foods, photo chemicals etc., the item is subject to deterioration, due to dryness, damage, spoilage, vaporisation etc., overtime during their normal storage period. For these items the deterioration must be taken into account which has tremendous influence on optimal inventory levels. Even in deteriorating items also it is well known that for a variable demand, (depending on some parameters like, time, selling price and both) the successive replenishment cycles diminish because of the fact that the balance is to be brought between the wastage due to deterioration, holding cost, and penalty due to shortages. Hence the deteriorating items with variable demand the planning is to be done for the whole finite horizon (Time of period of planning) by fixing the number of replenishment cycles each having variable length of time. This feature makes the inventory model more optimal in utilising the resources more effectively and to reduce the wastage.

\section{References}

[1]. Nahmias, S. (1982), "Perishable inventory theory: A review", Operations Research, Vol. 30, pp. 680 - 708. 
[2]. Rafat, (1991), "Survey of Literature on Continuously Deteriorating Inventory Models", Journal of the Operational Research Society, Vol. 42, No. 1, pp. $27-37$.

[3]. Giri ,B.C, Goyal, S. K. (2001), "Recent trends in modelling of deteriorating inventory", European Journal of Operations Research, Vol. 134, No. 1, pp. $97-112$.

[4]. Roy, T. \& ChaudhuriI, K. S. (2007), "An inventory model for a deteriorating item with price-dependent demand and special sale", International Journal of Operational Research, Vol. 2, No. 2, pp. $173-187$.

[5]. Pal, M. \& Ghosh, S. K. (2008), "An Inventory Model with Stock Dependent Demand and General Rate of Deterioration under Conditions of Permissible Delay in Payments", Opsearch, Vol. 44, No. 3, pp. 227 - 239.

[6]. Sana, S. S. (2007), "An Economic Order Quantity model for seasonal goods", International Journal of Operational Research, Vol. 3, No. 1-2, pp. $97-118$.

[7]. Panda, S., Senapathi, S. \& Basu, M. (2009), "A single cycle perishable inventory model with time dependent quadratic ramp-type demand and partial backlogging", International Journal of Operational Research, Vol. 5, No. 1, pp. $110-129$.

[8]. Roy, T. \& Chadhuri, K. S. (2010), "Optimal pricing for a perishable item under time-price dependent demand and time-value of money", International Journal of Operational Research, Vol. 7, No. 2, pp. 133 - 151

[9]. Dutta, T. K. \& Pal, A. K. (1992), "Deterministic inventory system with an inventory level dependent demand rate and shortages", Opsearch, Vol. 27, No. 4, pp. $213-224$.

[10]. Bhunia, A. K. \& MaittiI, M. (1997), "A deterministic inventory replenishment problem for deteriorating items with time dependent demand and shortages for the finite time horizon", Opsearch, Vol. 34, pp. $51-61$. 